\title{
Development of DVT in an operated case of cemented bipolar hemiarthroplasty during COVID pandemic: a case report
}

\author{
Neetin Pralhad Mahajan, Kartik Prashant Pande*, Pramod K Bagimani, Ravi Dadhaniya
}

Department of Orthopaedics, Grant Government Medical College and Sir JJ group of Hospitals, Mumbai, Maharashtra, India

Received: 16 November 2021

Accepted: 29 December 2021

\section{*Correspondence:}

Dr. Kartik Prashant Pande,

E-mail: kartik.pande0393@gmail.com

Copyright: (c) the author(s), publisher and licensee Medip Academy. This is an open-access article distributed under the terms of the Creative Commons Attribution Non-Commercial License, which permits unrestricted non-commercial use, distribution, and reproduction in any medium, provided the original work is properly cited.

\begin{abstract}
One of the most common treatment for fracture neck of femur in the elderly is bipolar hemi-arthroplasty which is associated with the patient being mobilized early, lower complication rate, longer implant life. Both uncemented and cemented arthroplasty have been associated with good outcomes, however cemented arthroplasty has higher incidences of DVT due to the thrombogenic potential of cement in addition to the hypercoagulability due to the femoral fracture. Hence, DVT remains a life-threatening complication of arthroplasty, despite the preventive measures owing also to certain genetic and acquired risk factors. We have a 70-year-old female patient, who presented to us with a post traumatic right sided displaced neck of femur with greater trochanter fracture following an alleged history of slip and fall at home who was operated with cemented bipolar hemi-arthroplasty. The patient developed deep vein thrombosis of the operated limb even after adequate mobilization with full weight bearing over the operated limb from post op day 2 and other adequate physiotherapy exercises such as hip/knee ROM exercises and ankle pump exercises. Although, our case report seems to be too far-fetched in terms of correlating this episode of DVT even after adequate mobilization from POD-2 to the ongoing COVID-19 pandemic causing a sub-clinical asymptomatic coronavirus infection causing an increased hypercoagulability of the blood as has been demonstrated by various studies, it does provide substantial evidence which warrants wider multi-centric studies in order to provide a definite correlation of the aforementioned scenario.
\end{abstract}

Keywords: Displaced neck of femur fracture, DVT, COVID-19 Pandemic, Cemented bipolar hemi-arthroplasty, Hypercoagulability

\section{INTRODUCTION}

One of the most common treatment for fracture neck of femur in the elderly is bipolar hemi-arthroplasty which is associated with the patient being mobilized early, lower complication rate, longer implant life. ${ }^{1}$ Both uncemented and cemented arthroplasty have been associated with good outcomes, however cemented arthroplasty has higher incidences of DVT due to the thrombogenic potential of cement in addition to the hypercoagulability due to the femoral fracture. ${ }^{2}$ Notably so, DVT remains a life- threatening complication of arthroplasty, despite the preventive measures owing also to certain genetic and acquired risk factors. Identification of these risk factors becomes clearly an aid in preventing such thromboembolic episodes secondary to DVT. Age, sex, pregnancy, increased body-mass index, hormone therapy, previous history of thrombo-embolism, and surgery are some of the major and notable risk factors which need to be taken care of during the pre-operative evaluation and post operative rehabilitation. Despite all such measures involving prophylactic measures, $15-20 \%$ of the patients who have 
undergone Total Hip Replacement develop subclinical DVT. ${ }^{3,4}$ Symptomatic DVT develops in about $2-4 \%$ of patients after 3 months of the procedure. ${ }^{5}$ These statistics tend to change in the Asian scenario with the incidence of venographically detected DVT after a major orthopaedic surgery without pharmacological prophylaxis was found to be as high as $50 \%$ after a hip fracture and ranging between $9.8 \%$ to $64.3 \%$ after THR..$^{6,7}$ These statistics could also be extrapolated to a hemiarthroplasty procedure owing to the almost same surgical technique as a total hip arthroplasty except the exclusion of the acetabular component replacement in the former. Owing to DVT being a lifethreatening complication of a cemented arthroplasty, various centres have advocated the use of pharmacological prophylaxis for decades to reduce the incidence and mortality associated with this complication. ${ }^{8}$

\section{CASE REPORT}

We have a 70-year-old female patient, who presented to us 1 day after an alleged history of slip and fall at home and sustained injury to the right hip. On preliminary imaging with $\mathrm{x}$-rays, the was diagnosed to have a right sided displaced basal-cervical neck of femur with greater trochanter fracture (Figure 1). After obtaining due fitness from the medicine and cardiology department, the patient was posted for surgery. The patient was operated with right sided cemented bipolar hemi-arthroplasty (Figure 2). The patient developed deep vein thrombosis of the operated limb diagnosed on POD-8 even after adequate mobilization with full weight bearing over the operated limb from post op day 2 and other adequate physiotherapy exercises such as hip/knee ROM exercises and ankle pump exercises.

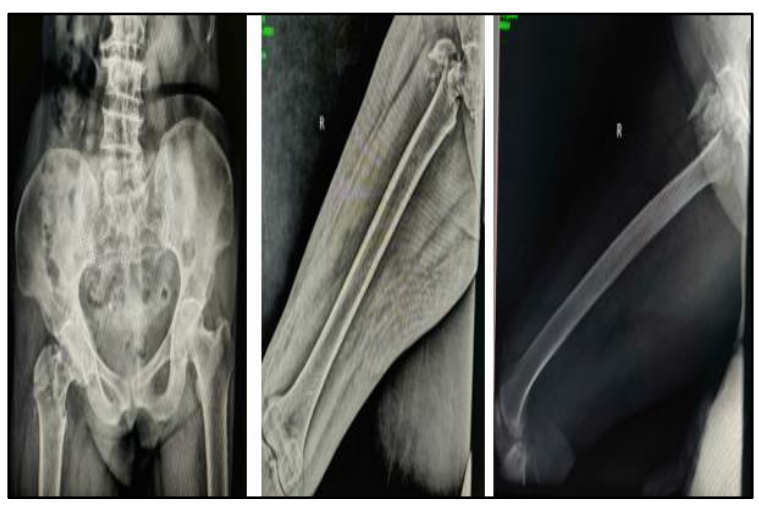

Figure 1: Post traumatic displaced neck of femur fracture.

\section{Surgical technique and course in the ward}

The patient was placed in a lateral decubitus position over the operating table. Induced under all aseptic precautions and under spinal and epidural anaesthesia. Scrubbing, panting and draping was done. A postero-lateral KocherLangenback's approach to the hip was employed. A cemented Bipolar hemi-arthroplasty with tension band wiring of the greater trochanter was done. Intra-operative period was unremarkable and the patient was vitally stable immediate post op. Abduction bar was applied.

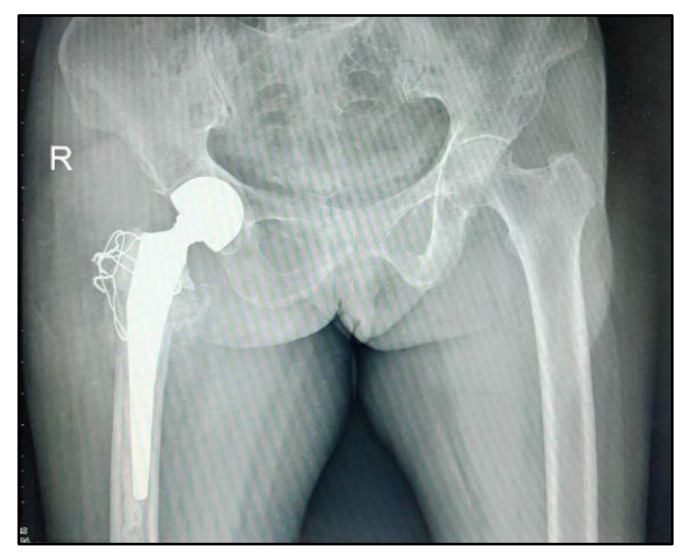

Figure 2: Post-operative X-ray showing right sided Bipolar hemiarthroplasty done.

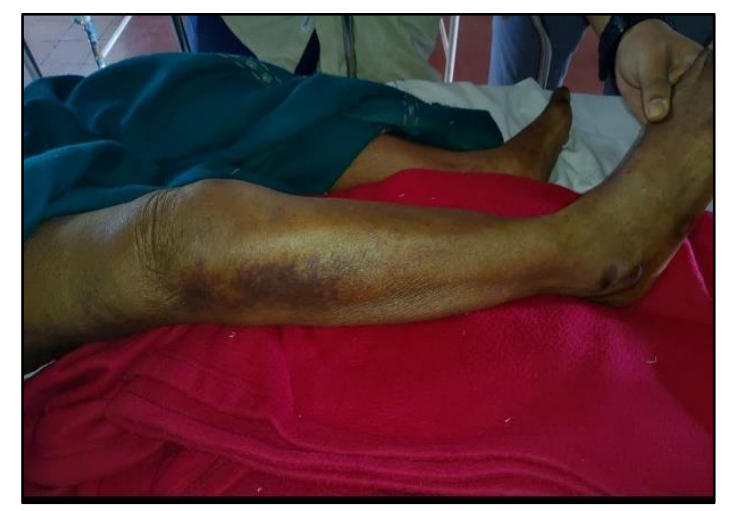

Figure 3: Swelling and reddish discoloration of the right lower limb from POD-8.

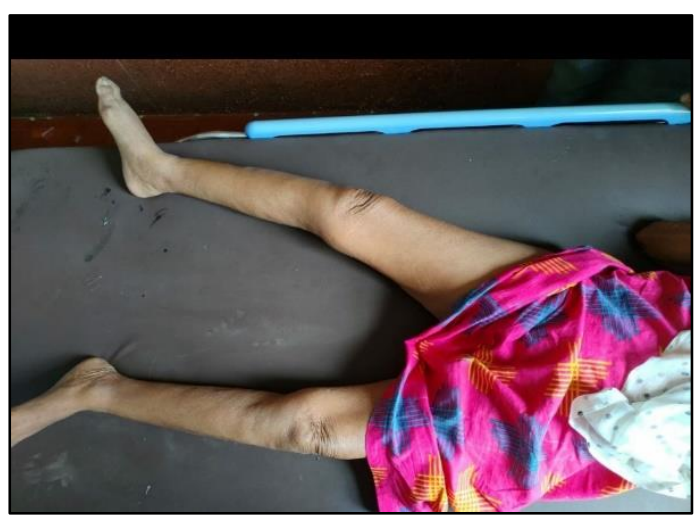

Figure 4: Reduction in swelling and local signs of inflammation after adequate immobilization.

On adequate pain relief by POD-2, the patient was mobilized bedside with hip in abduction and knee flexion extension exercises along with ankle pump were taught to the patient. Also, walker assisted full weight bearing mobilization was started for the patient from POD-2. The patient was vitally stable with no fresh complaints till 
POD-5 when she started complaining of pain and swelling over the right lower limb along with reddish discoloration over the antero-lateral aspect which was non-traumatic, insidious in onset and was gradually progressive which subsequently came to notice on POD-8 (Figure 3 ).

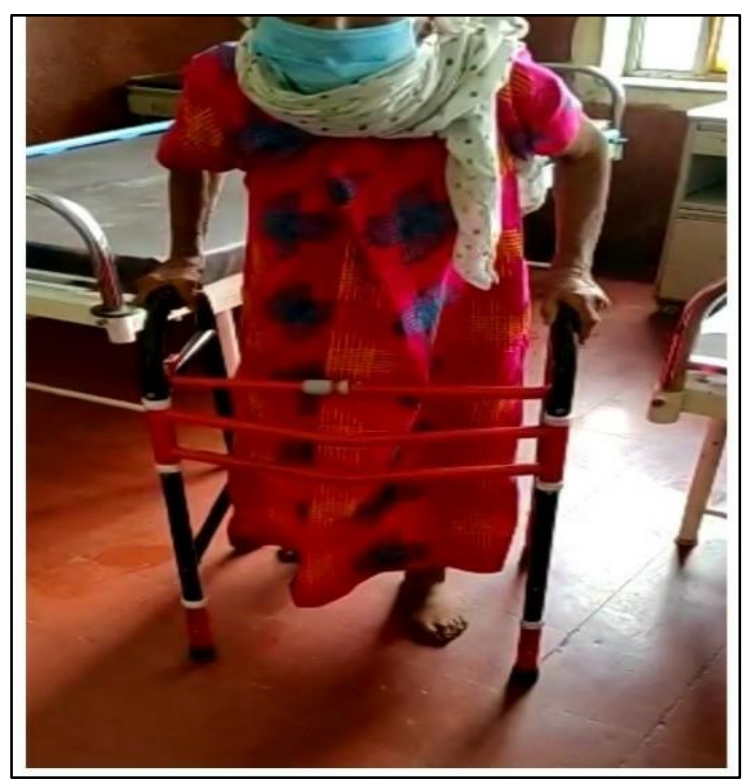

Figure 5: Patient weight bearing with walker assistance.

The swelling started initially in the ankle and foot, gradually progressing through the shin to the knee. It was associated with pain, which severe in intensity, dull aching type and diffuse in nature over the right lower limb, aggravated on limb movements and relieved on immobilization. USG Doppler of the limb showed non compressible thrombus within the popliteal vein, anterior and posterior tibial vein [POD-8]. The patient was started on IV heparin along with oral warfarin in appropriate dosages along with adequate limb elevation, strict immobilization and glycerine dressing of the affected limb after an adequate consultation from the cardio-vascular and thoracic surgery department (CVTS). The patient was monitored for any other thrombo-embolic episodes such as - breathlessness, headache, blurring of vision, abdominal pain, power loss in any of the limbs. Repeat doppler was done on POD-22 [15 days after the first doppler] which showed partial resolution of the thrombus as compared to the previous scan along with improvement in clinical symptoms and signs in terms of swelling, pain and redness (Figure 4), after which the patient was mobilized with full weight bearing after an appropriate advice from the CVTS department. The patient was discharged with oral warfarin and 3-weekly monitoring of PT/INR values which were maintained between 2-3. Repeat doppler at POD-37 [1 month after the first doppler] showed partial recanalization of the popliteal, anterior and posterior tibial vein. Throughout this course of treatment, the patient did not show any symptoms relating to thrombo-embolic episodes and was mobilized with full weight bearing after an initial phase of strict immobilization. At 4 months post op, repeat
USG Doppler was done which showed almost complete recanalization of the affected vessels with minimal residual occlusion. The patient had no fresh complaints at 4 months post operative follow up and was completely asymptomatic.

\section{DISCUSSION}

A bipolar hemiarthroplasty, or for that matter, any replacement procedure, which involves inserting a prosthesis for a joint is associated with an inherent prosthesis-related complications which include dislocation, peri-prosthetic fracture, aseptic loosening, bone cement implantation syndrome and infection. Each one of them with their associated importance with infection being one of the dreadful complications for the operating surgeon and the patient in terms of cost, morbidity and possible mortality. Apart from this, another deadly complication which is associated more so with cemented arthroplasty and increasing age (the 2 major contributing risk factors in this case) apart from those discussed previously, is the development of DVT, which if mismanaged can lead to significant morbidity and mortality. ${ }^{9}$ Ageing is one of the strongest and most prevalent risk factors for the development of DVT. This is caused due to ageing leading to increase in the prevalence of the conventional risk factors, development of new and age specific risk factors and accumulation of the same. The incidence of DVT was also found to be different in two differently skilled set of surgeons, longer duration of surgery was identified as the cause of increased incidence of DVT. ${ }^{10}$ Here in our case, a 70 -year-old female with no previous history of similar complication operated with a right sided cemented bipolar hemiarthroplasty developed DVT in the operated limb even after adequate mobilization and physiotherapy from POD-2 reiterating the results by various studies in favour of the use of prophylactic anticoagulants to prevent such a complication and further morbidity and possible mortality. One of the possible causes which we have considered in this case report is the prevalence of a sub clinical COVID-19 infection in asymptomatic patients with other risk factors, could be responsible for the hypercoagulable state of the body. As there are certain studies which corelate COVID-19 with an increased tendency of the body to form thrombus, even an adequate physiotherapy in the absence of prophylactic anticoagulant therapy, which otherwise wouldn't cause such a complication, led to the incidence of DVT, which needs further multi-centric studies for extrapolating our assumption. ${ }^{11}$

\section{CONCLUSION}

Although, our case report seems to be too far-fetched in terms of correlating this episode of DVT even after adequate mobilization from POD-2 to the ongoing COVID-19 pandemic causing a sub-clinical asymptomatic coronavirus infection causing an increased hypercoagulability of the blood as has been demonstrated by various studies, it does provide substantial evidence 
which warrants wider multi-centric studies in order to provide a definite correlation of the aforementioned scenario.

Funding: No funding sources

Conflict of interest: None declared

Ethical approval: Not required

\section{REFERENCES}

1. Maini PS, Talwar N, Nijhawan VK, Manish D. Results of cemented bipolar hemiarthroplasty for fracture of the femoral neck - 10-year study. Indian Journal of Orthopaedics. 2006;40:10.4103/00195413.34481.

2. Francis CW, Marder VJ, Evarts CM. Lower risk of thromboembolic disease after total hip replacement with non-cemented than with cemented prostheses. Lancet. 1986;1:769-71.

3. Engbers MJ, van Hylckama Vlieg A, Rosendaal FR. Venous thrombosis in the elderly: incidence, risk factors and risk groups. J Thromb Haemost. 2010;8:2105-12.

4. Geerts WH, Pineo GF, Heit JA. Prevention of venous thromboembolism: the Seventh ACCP Conference on Antithrombotic and Thrombolytic Therapy. Chest. 2004;126:338S-400S.

5. White RH, Zhou H, Romano PS. Incidence of symptomatic venous thromboembolism after different elective or urgent surgical procedures. Thromb Haemost. 2003;90:446-55.
6. Dhillon KS, Askander A, Doraismay S. Postoperative deep-vein thrombosis in Asian patients is not a rarity: a prospective study of 88 patients with no prophylaxis. J Bone Joint Surg Br. 1996;78:42730.

7. Yoo MC, Kang CS, Kim YH. A prospective randomized study on the use of nadroparin calcium in the prophylaxis of thromboembolism in Korean patients undergoing elective total hip replacement. Int Orthop. 1997;21:399-402.

8. Dahl OE, Caprini JA, Colwell CW, Jr, Frostick SP, Haas S, Hull RD. Fatal vascular outcomes following major orthopedic surgery. Thromb Haemost. 2005;93(5):860-866.

9. Rinecker H. New clinico-pathophysiological studies on the bone cement implantation syndrome. Arch Orthop Trauma Surg. 1980;97:263-74.

10. López JA, Chen J. Pathophysiology of venous thrombosis. Thromb Res. 2009;123:S30-4.

11. Biswas S, Thakur V, Kaur P, Khan A, Kulshrestha S, Kumar P. Blood clots in COVID-19 patients: Simplifying the curious mystery. Med Hypotheses. 2021;146:110371.

Cite this article as: Mahajan NP, Pande KP, Bagimani PK, Dadhaniya R. Development of DVT in an operated case of cemented bipolar hemiarthroplasty during COVID pandemic: a case report. Int J Res Orthop 2022;8:283-6. 